Article

\title{
Corrosion Behavior and Surface Properties of PVD Coatings for Mold Technology Applications
}

\author{
Luigi D'Avico ${ }^{1}$, Ruben Beltrami ${ }^{2}$, Nora Lecis ${ }^{2}$ and Stefano P. Trasatti ${ }^{3, *}$ (I) \\ 1 Institute for Building Materials, ETH Zurich, 8093 Zurich, Switzerland; davicoluigi@ifb.baug.ethz.ch \\ 2 Department of Mechanical Engineering, Politecnico di Milano, 20156 Milan, Italy; \\ ruben.beltrami@polimi.it (R.B.); nora.lecis@polimi.it (N.L.) \\ 3 Department of Environmental Science and Policy, Università degli Studi di Milano, Milan 20133, Italy \\ * Correspondence: stefano.trasatti@unimi.it; Tel.: +39-02503-14207
}

Received: 28 August 2018; Accepted: 19 December 2018; Published: 22 December 2018

\begin{abstract}
Chrome plating is still one of the best solutions to coat martensitic steel used in the molding of plastics and rubbers. However, current stringent regulations on environmental impact call for more sustainable processes. In the present work, some physical vapor deposition (PVD) nitride coatings were produced on $\mathrm{X} 155 \mathrm{CrMoV} 12$ steel and characterized in terms of both corrosion behavior and surface properties. Results indicated that titanium-based PVD coatings could be a valuable alternative to chromium-based coatings as they exhibited a good compromise between corrosion and surface properties. AlTiN and TiN PVD coatings exhibited adequate hardness for plastic mold applications, with AlTiN reaching hardness as high as $2000 \mathrm{HV}$. Moreover, the critical loads and adhesion properties were found to be definitely better than those of chromium-based coatings. From a corrosion point of view, the presence of multilayers in AlTiN did not seem to be beneficial as the breakdown potential for TiN (single layer) was ca. $1.1 \mathrm{~V}$ vs. saturated calomel electrode (SCE) compared to $0.85 \mathrm{~V}$ vs. SCE for AlTiN in aggressive media $(\mathrm{NaCl})$.
\end{abstract}

Keywords: PVD coatings; mechanical properties; surface analysis; corrosion

\section{Introduction}

The plastics mold industry shows great attractiveness due to the high-pressure forming process in which the molten plastic material is squeezed directly into a mold cavity by the application of heat and pressure to conform to the shape of the mold. However, compression molding processes also have disadvantages, such as low production rate, and they need to work with flat or moderately curved parts. The problem is partially solved by using brushes that eliminate the excess rubber resulting from the molding process. Unfortunately, this practice causes mechanical stress, corrosion, and wear problems, thus calling for the need of coatings with high hardness and corrosion resistance [1-3]. For a long time, chromium plating has been the best solution for injection molding tool applications owing to its low cost as well as high corrosion and wear resistance (low adhesion to most plastics). However, it is well known that electrolytic hard chromium plating needs to be replaced with more cleaner and sustainable processes due to its environmental and health problems [4]. Different coating technologies, such as chemical vapor deposition (CVD), thermal spraying, and physical vapor deposition (PVD) have emerged as alternatives to chromium during the past decades [5,6]. PVD coatings produced by arc plasma technology exhibit high strength and excellent adhesion properties, thus enabling it to coat almost every type of tool. In particular, nitride PVD coatings have been successfully used in industrial applications for their mechanical properties and wear and corrosion resistance [7-9]. As an industrial example of these features, Wang [10] studied PVD coatings of TiN, TiAlN, and CrN on tool steels in contact with molten aluminum and concluded that this type of coating can provide significant corrosion 
and erosion resistance. Wear, tensile, and fatigue behavior were also studied to compare PVD coatings that were Ti-based and Cr-based [11]. Tribological aspects of PVD produced by arc plasma showed a lower friction coefficient and wear rate in different testing conditions [12-14]. Cathodic Arc PVD process can produce very dense layers with little or no porosity, forming a single-layer or multilayer structure on the substrate [15]. Okumiya and Griepentrog discussed the influence of single-layer or multilayers on mechanical and tribological properties, showing that multilayers do not seem to confer positive effects because the lifetime of the coatings is restricted by the poor adhesion of the coatings on the steel substrates [16]. Conversely, PalDey and Deevi concluded that the presence of a large number of interfaces between individual layers of a multilayered structure results in a marked increase in hardness and strength [17]. Furthermore, Kappl et al. claimed that definite improvements in the corrosion behavior of hard coatings can be obtained by a proper multilayer structure [18].

The aim of the present work was to characterize several PVD coatings, in terms of both corrosion behavior and surface properties, as potential candidates for the replacement of hard chromium plating in the plastic mold industry. The present experimental work arose from an emerging need to substitute chrome plating as a unique deposition process of hard coatings with more sustainable deposition processes. The choice of using PVD coatings as an alternative is becoming mandatory due to the actual market demand. In this respect, the PVD coatings used in this study were chosen based on the experience of involved industrial producers and end-users as well as on market availabilities. Five PVD coatings-TiN, AlTiN, CrN/Cr, $\mathrm{CrN} / \mathrm{Nb}$, and $\mathrm{ZrN}$-were selected among the most used in current industrial applications and were deposited on $\mathrm{X} 155 \mathrm{CrMoV} 12$. The corrosion behavior was investigated by cyclic potentiodynamic polarization in two synthetic solutions: $0.1 \mathrm{M} \mathrm{Na}_{2} \mathrm{SO}_{4}$ and $0.1 \mathrm{M} \mathrm{NaCl}$. The coating adhesion was evaluated by scratch test, and the relative critical load was determined according to ASTM G171 [19]. Hardness and roughness measurements were carried out for each coating with the aim of checking the required surface properties for the specific applications.

\section{Materials and Methods}

\subsection{Steel and Coatings}

The substrate was a martensitic stainless steel coded as X155CrMoV12 (K110 Bohler steel; DIN 1.2379, AISI D2), whose nominal chemical composition is C 1.55\%; Si 0.30\%; Mn 0.30\%; Cr 11.5\%; Mo $0.70 \%$; V $1.00 \%$. The material was supplied in the form of round bar that was $30 \mathrm{~mm}$ in diameter, and 5-mm-thick specimens were cut (Figure 1). Before coating, each specimen was quenched and tempered to a hardness of $26 \mathrm{HRC}$. Then, the thermal treatment samples were mirror-polished using abrasive papers, diamond paste, and finally alumina suspension of $0.05 \mu \mathrm{m}$.

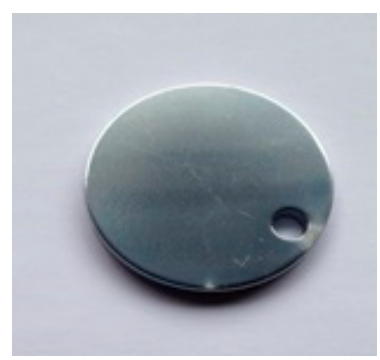

Figure 1. Small disk, diameter $30 \mathrm{~mm}$, of $\mathrm{X} 155 \mathrm{CrMoV} 12$ steel.

Five PVD coatings were produced by cathodic arc deposition technology, under pressure control, equipped with a rotating barrel. The standard for plastic molding is chromium plating, so two Cr-based PVD coatings were chosen. In addition, as Ti-based and ZrN PVD coatings are also available in the market, we decided to investigate these kinds of PVDs, which have also been supported by the involved industries as possible future alternatives to Cr-based PVD coatings. Three disk steel samples were used for each PVD coating. The main process parameters used for each PVD coating are 
listed in Table 1; in the case of multilayer coatings, the number of layers is also reported. Specifically, the sequence of layers was as follows: for AlTiN: $1^{\circ} \mathrm{TiN}, 2^{\circ}$ AlTiN, $3^{\circ}-7^{\circ}(\mathrm{AlTiN}+\mathrm{TiN}) \times 5,8^{\circ} \mathrm{AlTiN}$; for $\mathrm{CrN} / \mathrm{Nb}: 1^{\circ} \mathrm{Cr}, 2^{\circ} \mathrm{CrN}, 3^{\circ} \mathrm{CrN}+\mathrm{NbN}, 4^{\circ} \mathrm{NbN}$; and for $\mathrm{CrN} / \mathrm{Cr}: 1^{\circ} \mathrm{CrN}, 2^{\circ} \mathrm{Cr}, 3^{\circ} \mathrm{CrN}, 4^{\circ} \mathrm{Cr}$. For multilayer coatings, the temperature and pressure of each layer deposition were the same during the process; for every coating, the first layer was thicker to improve adhesion.

Table 1. Summary of physical vapor deposition (PVD) coatings, composition layer, and process parameters.

\begin{tabular}{cccc}
\hline Coating & Type & Deposition Temperature $\left({ }^{\circ} \mathbf{C}\right)$ & Deposition Pressure $\left(\mathbf{k g} / \mathbf{m} \cdot \mathbf{s}^{2}\right)$ \\
\hline $\mathrm{CrN} / \mathrm{Cr}$ & Multilayer (4 layers) & 350 & 1.5 \\
$\mathrm{CrN} / \mathrm{Nb}$ & Multilayer (4 layers) & 350 & 2.5 \\
$\mathrm{AlTiN}$ & Multilayer (8 layers) & 450 & 1.5 \\
$\mathrm{TiN}$ & Single layer & 450 & 1.5 \\
$\mathrm{ZrN}$ & Single layer & 450 & 1.5 \\
\hline
\end{tabular}

Before the deposition, the specimens were cleaned in an ultrasonic bath containing alkaline solvents, followed by preliminary ion etching to remove any trace of possible surface contaminants. After cleaning, substrates were loaded into a vacuum chamber $\left(10^{-5} \mathrm{mbar}\right)$ and heated for $1-2 \mathrm{~h}$ at temperatures in the range of $350-450{ }^{\circ} \mathrm{C}$. When the heating process was completed, argon was injected into the chamber while a high voltage was applied to the substrates (bias voltage, typically $800 \mathrm{~V}$ ) with $\mathrm{N}_{2}$ as sole reactant (plasma formed). Coatings were deposited for $30 \mathrm{~min}$. After deposition, cooling was performed in vacuum at temperature below $180^{\circ} \mathrm{C}$. Finally, nitrogen was injected into the chamber up to atmospheric pressure to avoid oxidation processes.

\subsection{Hardness and Roughness Measurements}

Hardness measurements were obtained by a Fester FM-700 with a penetration depth between $0.5-2 \mu \mathrm{m}$. As this range is comparable to the thicknesses of the investigated coatings, the measured hardness can better reflect the interaction between PVD layers and metallic substrate. Keeping in mind that the trend, rather than the absolute value, is more relevant in the present study, two different applied loads were used: $25 \mathrm{~g}$ ( $0.25 \mathrm{~N}$ of applied force) and $100 \mathrm{~g}$ ( $1 \mathrm{~N}$ of applied force). The surface roughness $\left(R_{\mathrm{a}}\right)$ of the PVD coatings was measured by a mechanical Bruker Dektak XT profilometer (Billerica, MA, USA). Each measurement was repeated five times for statistical purpose.

\subsection{Coating Adhesion}

In order to measure coating adhesion, scratch tests were performed [20-23]. Coatings were tested and compared using a CSM micro-combi tester (Graz, Austria). During the tests, scratches were performed on samples with a sphere-conical stylus (tip radius ranging $200 \mu \mathrm{m}$ ), which was drawn across the sample at constant speed $(12.59 \mathrm{~N} / \mathrm{min})$ under an incremental load (0.03 to $30 \mathrm{~N}$ ). Critical loads (corresponding to LcI) were determined by measuring the acoustic emission corresponding to the formation of the first crack detected by a specific sensor. Each measurement was replicated five times with reproducibility.

\subsection{Scanning Electron Microscopy}

The average thickness $(d)$ and elemental analysis of the deposited films were determined by SEM using a ZEISS EVO 50 (Oberkochen, Germany) equipped with energy-dispersive X-ray spectroscopy. For each coating, the thickness was measured during SEM examination of cross-sectioned samples observed at different magnifications. The measurements were carried out along different locations of three samples for each coating, and the final result was given as range of values. 


\subsection{Corrosion Experiments}

The corrosion behavior of each coating was carried out using an electrochemical cell designed ad hoc: O-ring type cells with $1 \mathrm{~cm}^{2}$ active surface area of coated material as working electrode, exposed by means of a circular hole on the cell bottom. The electrode setup was completed by a Pt coil as a counter electrode and a saturated calomel electrode (SCE) as a reference electrode, connected to the cell via a U-tube and a Luggin's capillary. All experiments were performed at room temperature and under open-air conditions. The electrochemical system was connected to a Gamry Interface 1000 Multipotentiostat with four channels, coupled to a computer with dedicated software, allowing more simultaneous experiments. Single-cycle anodic polarizations were conducted in sodium sulfate solution $\left(0.1 \mathrm{M} \mathrm{Na}_{2} \mathrm{SO}_{4}, \mathrm{pH} 5.5 \pm 0.4\right)$ as well as in a moderately aggressive chloride solution $(0.1 \mathrm{M} \mathrm{NaCl}, \mathrm{pH} 5.5 \pm 0.4)$. Scan rate of $0.1667 \mathrm{mV} \cdot \mathrm{s}^{-1}$, equilibration time of $5 \mathrm{~min}$, and reverse current of $2 \mathrm{~mA} / \mathrm{cm}^{2}$ were used. Each experiment was replicated at least twice until the same behavior was confirmed. A typical polarization curve is shown in Figure 2, where open arrows represent the forward and reverse branches, respectively. The main electrochemical features are also shown.

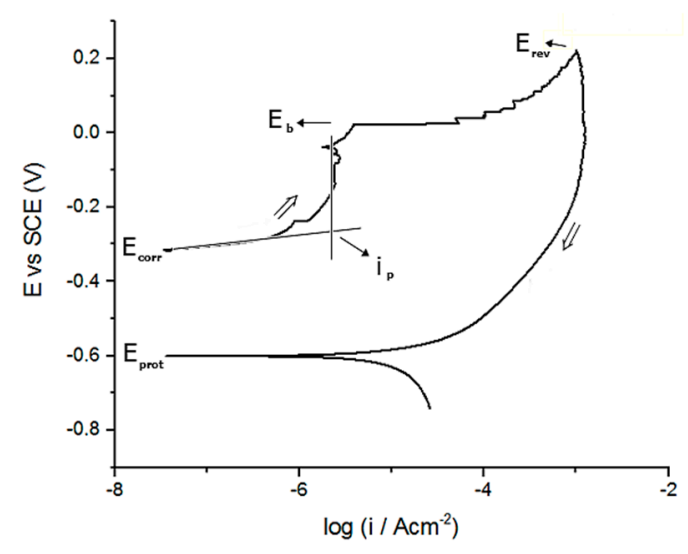

Figure 2. Typical polarization curve of a material exhibiting passive behavior (forward curve) but suffering localized corrosion (reverse curve). $E_{\text {corr }}$, corrosion potential; $E_{\text {prot, }}$, protection potential; $E_{\mathrm{b}}$, breakdown potential; $E_{\mathrm{rev}}$, reverse potential; $i_{\mathrm{p}}$, passive current density.

The reported curve referred to a material undergoing localized corrosion. In this case, the reverse curve was below the forward scan (negative hysteresis). The opposite situation (positive hysteresis) was obtained for a material resistant to corrosion.

\section{Results and Discussion}

\subsection{Hardness and Roughness}

The main results of this experimental part are summarized in Table 2. Regarding the hardness measurements, two different tests were performed: the first with an applied load of $0.25 \mathrm{~N}$ and the second with an applied load of $1 \mathrm{~N}$. The applied loads were used in order to mimic the industrial application of plastic molding. As expected, AlTiN PVD coating showed the best performance at both applied loads. Conversely, TiN exhibited the lowest hardness. It must be noted that TiN has a very low thickness $(0.5-1.0 \mu \mathrm{m})$, consequently, its hardness could be strongly influenced by penetration depth. As a confirmation of this, a new measurement at a lower applied load $(0.1 \mathrm{~N})$ was carried out and a hardness of $913 \pm 110 \mathrm{HV}_{0.01 / 10}$ was obtained. This value is comparable with the typical hardness of hard chromium plating (850-1100 Vickers). Depending on the applied load, similar hardness was observed among the other three PVD coatings. This range of values is compatible with the typical hardness required for rubber and plastic molding applications [2]. 
Table 2. Average values of hardness $\left(\mathrm{HV}_{0.025 / 10}\right.$ and $\left.\mathrm{HV}_{0.1 / 10}\right)$, roughness $(R)$, and critical load (LcI) for each PVD coating.

\begin{tabular}{ccccc}
\hline Coating & $\boldsymbol{H}\left(\mathbf{H V}_{\mathbf{0 . 0 2 5 / 1 0}}\right)$ & $\boldsymbol{H}\left(\mathbf{H V}_{\mathbf{0 . 1} / \mathbf{1 0}}\right)$ & $\boldsymbol{R}\left(\boldsymbol{R}_{\mathbf{a}}, \mathbf{n m}\right)$ & $\mathbf{L c I} \mathbf{( N )}$ \\
\hline $\mathrm{CrN} / \mathrm{Cr}$ & $1736 \pm 37$ & $1042 \pm 50$ & $16 \pm 8$ & $10 \pm 2$ \\
$\mathrm{CrN} / \mathrm{Nb}$ & $1440 \pm 75$ & $1130 \pm 30$ & $46 \pm 6$ & $5 \pm 1$ \\
$\mathrm{AlTiN}$ & $2758 \pm 160$ & $2116 \pm 60$ & $50 \pm 10$ & $16 \pm 2$ \\
$\mathrm{TiN}$ & $649 \pm 40$ & $452 \pm 25$ & $50 \pm 10$ & $13 \pm 4$ \\
$\mathrm{ZrN}$ & $1516 \pm 170$ & $1331 \pm 30$ & $75 \pm 5$ & $11 \pm 2$ \\
\hline
\end{tabular}

Multilayer Cr-based PVD coatings showed a similar performance at high applied load (1 N), while the more brittle layer of $\mathrm{NbN}$ seemed to affect the total hardness of the coating at $0.2 \mathrm{~N}$. This finding was also confirmed in the scratch test. With respect to the average surface roughness of the tested coatings, some interesting observations could be drawn by scrutinizing the reported data $\left(R_{\mathrm{a}}\right.$, Table 2). For the specific application, a high value of roughness is also required $[2,6]$. Moreover, releasing agents affecting the wettability at the emulsion/coating interface during the molding process are commonly used [2,6,17]. We found that AlTiN, TiN, and ZrN PVD coatings again showed better performance than chromium-based coating, exhibiting a higher average roughness factor; indeed, the $\mathrm{CrN} / \mathrm{Cr}$ showed roughness values three times less. However, when the last layer was different from chromium $(\mathrm{CrN} / \mathrm{Nb})$, both hardness and roughness approached the same values for AlTiN, TiN, and ZrN PVD coatings.

\subsection{Scratch Test}

Coating adhesion was evaluated using the scratch test, and the results are summarized in Table 2. All coatings showed similar values apart from $\mathrm{CrN} / \mathrm{Nb}$, which had low LcI. In Figure 3, an example of results obtained by measurement on AlTiN PVD coating is shown.

Critical load is not enough to fully evaluate adhesion properties of the coating. For multilayer coatings, both cohesive (inside the same layer) and adhesive (between different layers and coating/substrate) forces should be considered. Scratch tests, together with microscopic observation of the shape of the cracks (Figure 4), allowed us to determine which forces prevailed. We found that if the crack followed the scratch direction, cohesive forces outweighed adhesive ones (see Figure 4a) as in the case of AlTiN. Conversely, in the $\mathrm{ZrN}$ coating, cracks were oriented in the opposite direction with respect to the scratch, meaning adhesive forces prevailed over cohesive ones (Figure $4 a, b)$. The cracks on $\mathrm{CrN} / \mathrm{Cr}$ showed an intermediate shape (Figure 4c), indicating that adhesive and cohesive forces were comparable.

Analyzing the scratch growths, it was possible to point out the damage phenomena involved. Figure 5 shows a $\mathrm{CrN} / \mathrm{Nb}$ SEM micrograph of the surface after the scratch. $\mathrm{CrN} / \mathrm{Nb} \mathrm{PVD}$ coating showed the lowest value of first critical load (LcI was $5 \mathrm{~N}$ ). From the higher magnification, the brittleness and the poor adhesion of the $\mathrm{NbN}$ top layer could be observed. A brittle failure and spallation of the $\mathrm{NbN}$ uncovering a large area of underlying $\mathrm{CrN}$ layer could also be observed. Furthermore, there were visible $\mathrm{NbN}$ chips and small to large cracks on the surface. This delamination could be possibly detrimental to corrosion performance of the coating, particularly in aggressive media such as $\mathrm{NaCl}$ solution.

As a comparison, TiN single layer PVD coating after the scratch is shown in Figure 6. In this case, the adhesion of the coating was higher (LcI was $13 \mathrm{~N}$ ) than $\mathrm{CrN}$. The damage mechanism of the scratch showed a plastic deformation with presence of arc tensile cracks. Finally, some parts of TiN PVD coating peeled off partially, thus uncovering the substrate clearly visible at the end of the scratch. 


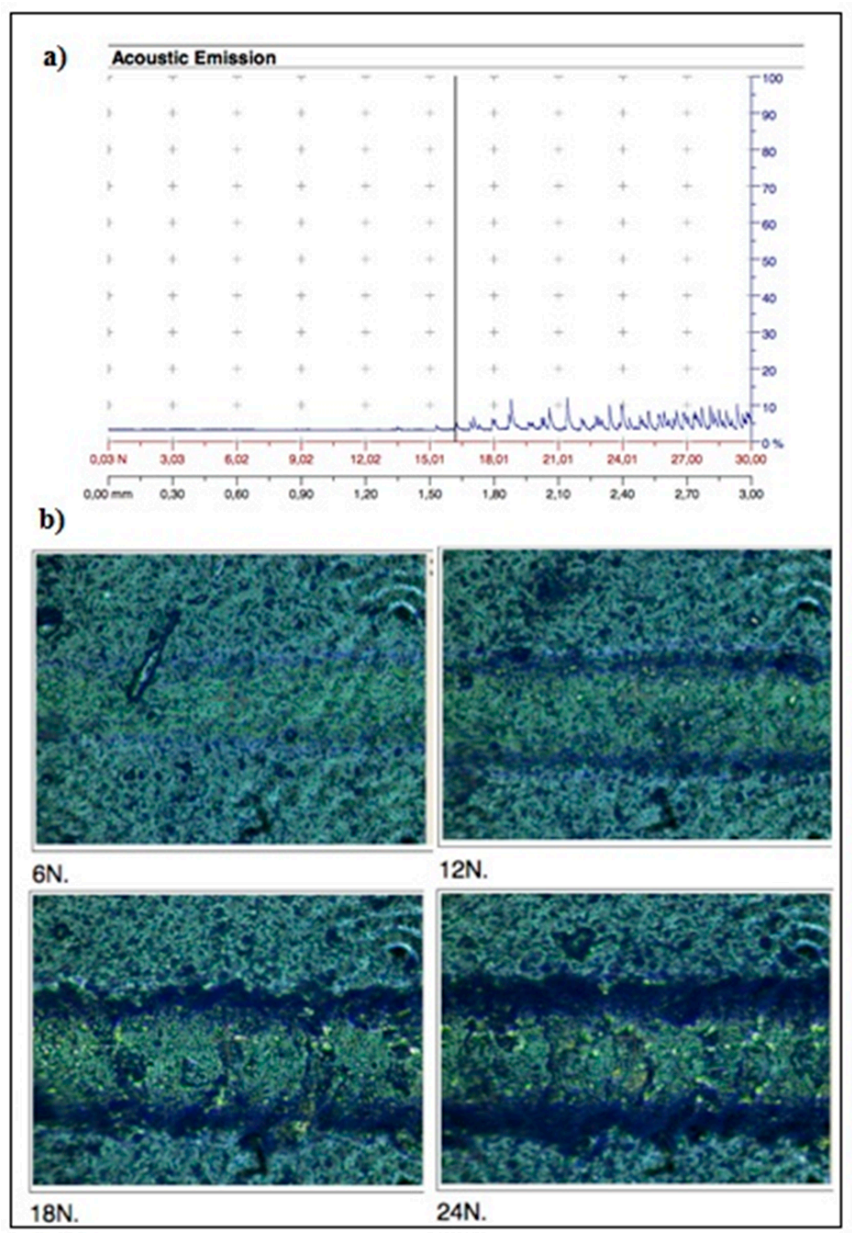

Figure 3. (a) Acoustic emission of the AlTiN coating and (b) optical micrographs of the AlTiN coating scratch.
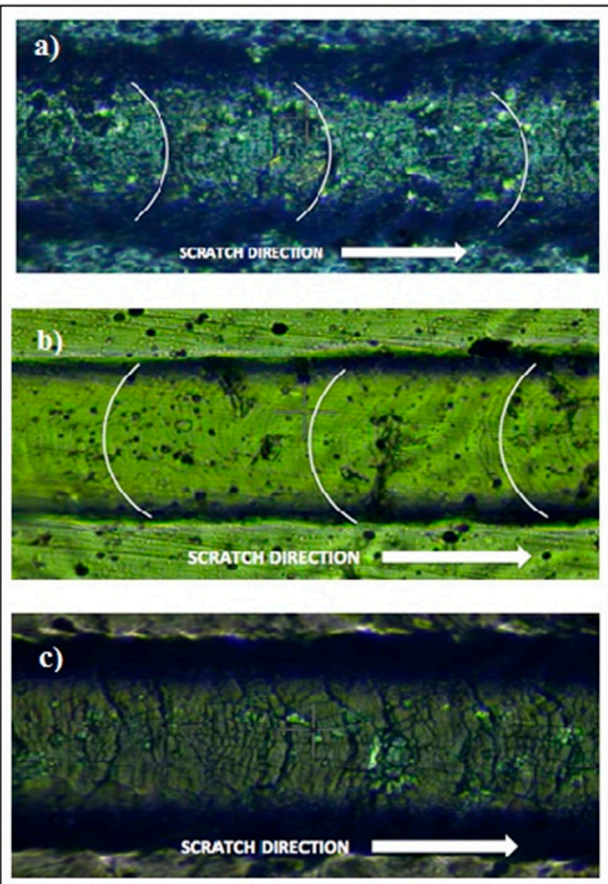

Figure 4. Shape of cracks in (a) AlTiN sample, (b) $\mathrm{ZrN}$ sample, and (c) $\mathrm{CrN} / \mathrm{Cr}$ sample. 


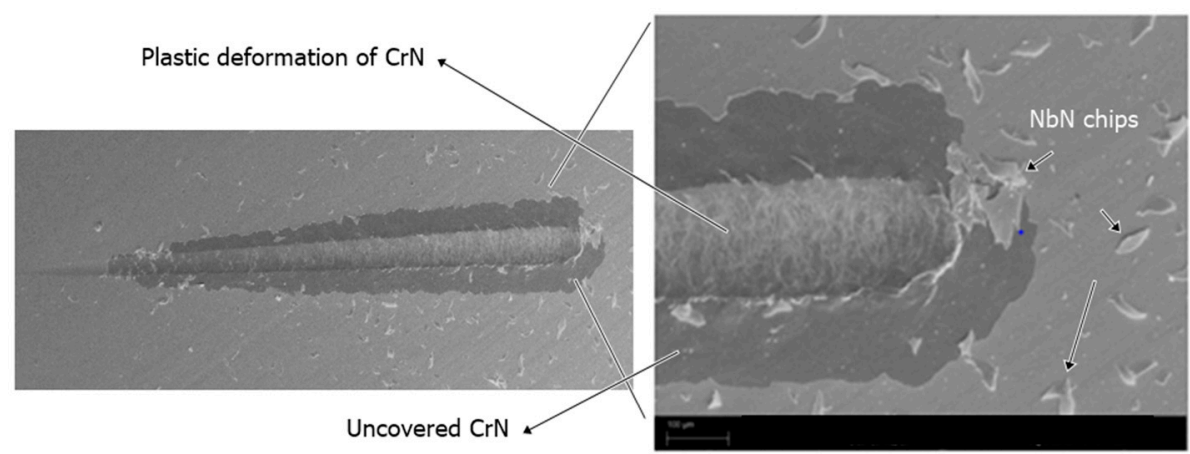

Figure 5. SEM image of $\mathrm{CrN} / \mathrm{Nb}$ PVD coating after scratch test.

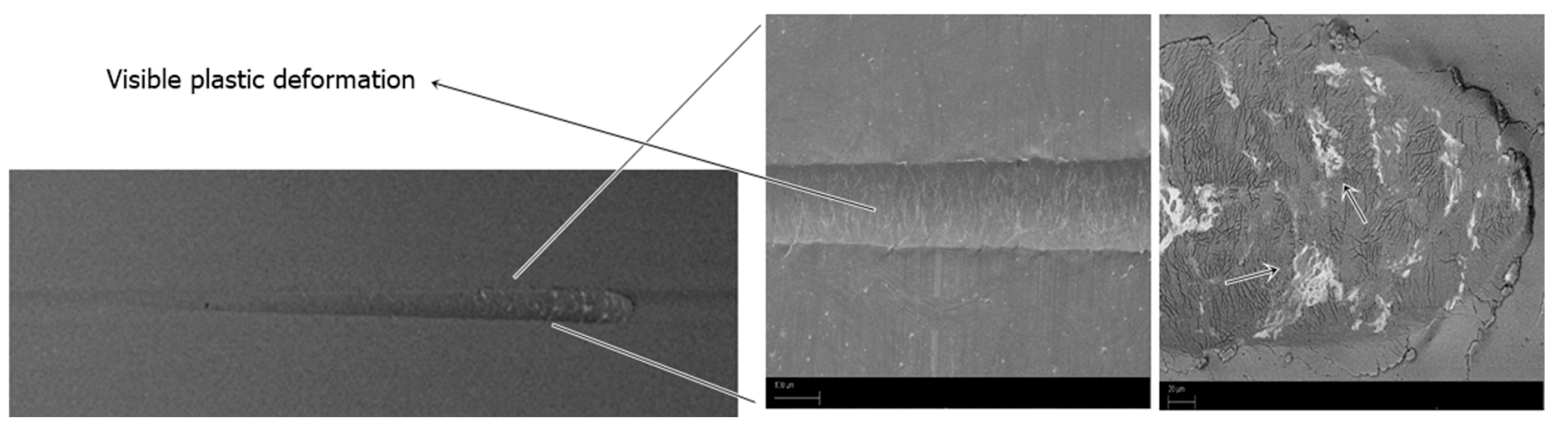

Figure 6. SEM image of TiN PVD coating after scratch test.

\subsection{Scanning Electron Microscopy}

SEM cross-section micrographs of $\mathrm{ZrN}$ and AlTiN are shown in Figure 7 as an example of single-layer and multilayer coatings, respectively. In the case of multilayer coating, it was possible to observe a clear succession of the layers (Figure 7). All coatings appeared adherent, compact, and uniformly distributed along the surface profile; only $\mathrm{CrN} / \mathrm{Cr}$ showed the presence of some defects, mainly in the form of cracks. Using SEM, it was also possible to evaluate the thickness; these values are listed in Table 3. The variation of the thicknesses of Cr-based and Ti-based PVD coatings was in a fairly small range. This is relevant when comparing coating properties like adhesion, hardness, and roughness as they can be strictly related to the thickness.

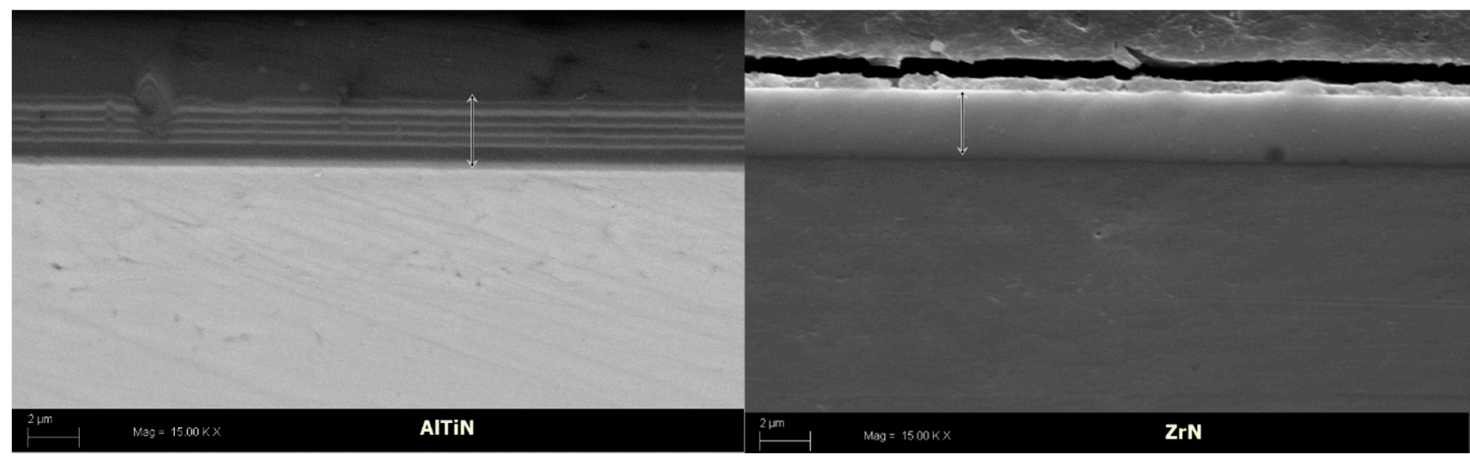

Figure 7. SEM micrographs of (a) AlTiN coating (multilayer) and (b) ZrN coating (single layer).

As can be seen in Figure 7a, the nitride layers were clearly visible on the surface of the samples. The coatings were homogeneously distributed without defects or discontinuities like inclusions, nodules, droplets and microcracks. ZrN single layer (Figure 7b) was the thickest PVD coating, and TiN was the thinnest one. 
Table 3. PVD coatings thickness. Thickness range was measured as explained in Section 2.4.

\begin{tabular}{cc}
\hline Coating & Thickness $(\mu \mathrm{m})$ \\
\hline $\mathrm{CrN} / \mathrm{Cr}$ & $1.0-1.5$ \\
$\mathrm{CrN} / \mathrm{Nb}$ & $1.5-2.0$ \\
$\mathrm{AlTiN}$ & $1.5-2.0$ \\
$\mathrm{TiN}$ & $0.5-1.0$ \\
$\mathrm{ZrN}$ & $3.0-3.5$ \\
\hline
\end{tabular}

\subsection{Corrosion Behavior}

Corrosion resistance was investigated on the five coatings in $0.1 \mathrm{M} \mathrm{Na}_{2} \mathrm{SO}_{4}, \mathrm{pH} 5.5 \pm 0.4$, and in $0.1 \mathrm{M} \mathrm{NaCl}, \mathrm{pH} 5.5 \pm 0.4$, by means of single anodic cyclic polarization. The two types of solutions were selected to mimic mild and aggressive environments, respectively [24,25]. The electrochemical behavior of bare steel in $\mathrm{NaCl}$ solution is shown in Figure 8. The steel exhibited an active behavior, with the current density continuously increasing with the potential and a reverse branch forming a wide negative hysteresis. This curve is typical for a material undergoing uniform corrosion. The same curve was obtained in $\mathrm{Na}_{2} \mathrm{SO}_{4}$ solution but at slightly lower current densities.

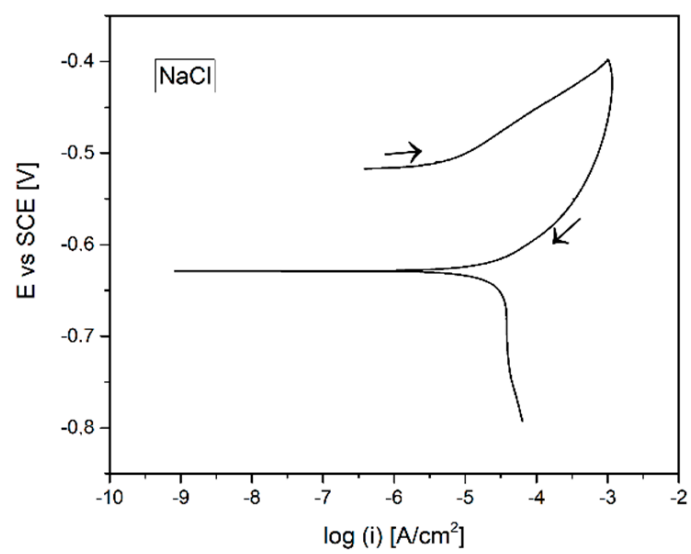

Figure 8. Polarization curve of steel in $0.1 \mathrm{M} \mathrm{NaCl}$.

After PVD deposition and independently of coating type, steel drastically improved its performance, moving from an active to a passive behavior. As an example, the polarization curves of titanium-based PVD coatings are shown in Figure 9.
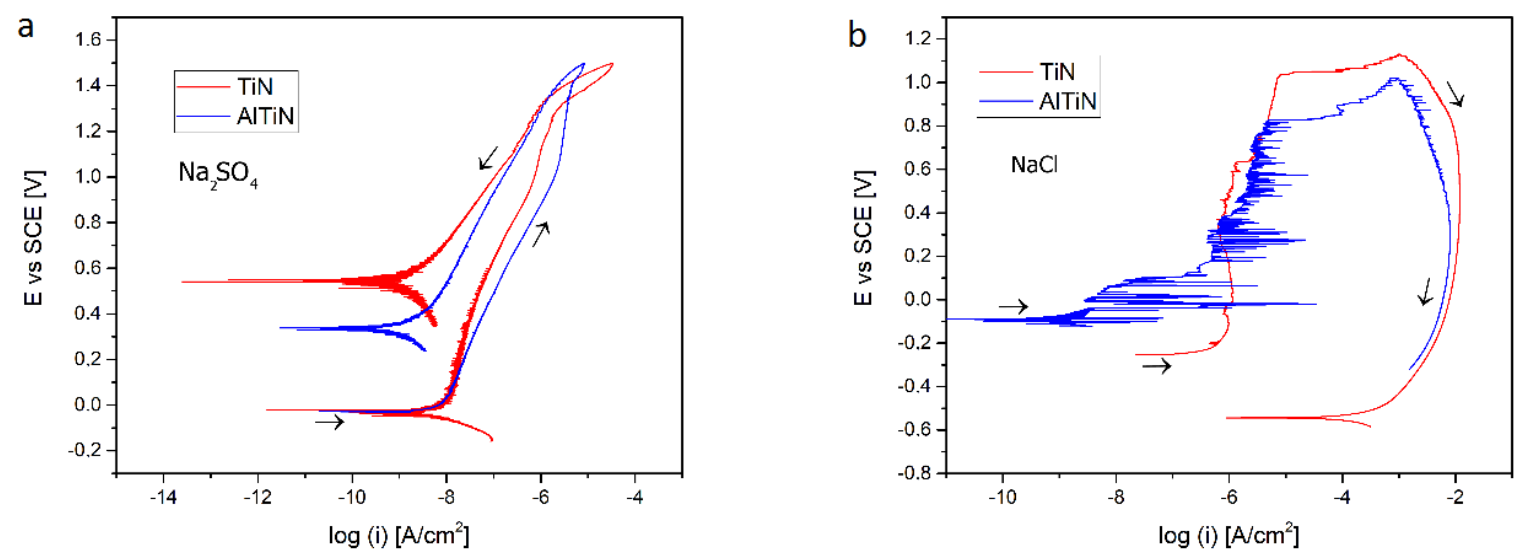

Figure 9. Polarization curves of steel coated with TiN and AlTiN PVD coatings in $0.1 \mathrm{M} \mathrm{Na}_{2} \mathrm{SO}_{4}(\mathbf{a})$ and in $0.1 \mathrm{M} \mathrm{NaCl}(\mathbf{b})$. 
In $\mathrm{Na}_{2} \mathrm{SO}_{4}$ solution, TiN and AlTiN both showed a passive behavior with a positive hysteresis and a wide passive potential window that started to break at ca. $1.3 \mathrm{~V}$ vs. SCE. These features indicated a great stability of the coatings in the tested solution. In $\mathrm{NaCl}$ solution, a passive behavior (forward branch) was still clearly visible, but the breakdown potential of the two coatings was markedly lower than that obtained in $\mathrm{Na}_{2} \mathrm{SO}_{4}$, reaching values as low as 0.85 and $1.1 \mathrm{~V}$ vs. SCE for AlTiN and TiN, respectively. This premature rupture of the coatings was accompanied by the initiation (and subsequent propagation at increasing potentials) of localized corrosion phenomena, thus leading to a wide negative hysteresis in the reverse branch. A strict analysis of the forward branch of the curves in $\mathrm{NaCl}$ showed that despite both coatings exhibiting a passive behavior, the presence of appreciable oscillations of the electrochemical signal of AlTiN during the recording of the forward branch was indicative of a coating showing certain instability in the solution under examination. This was clearly reflected in the coating breakdown potential, which was much lower than that of TiN. On the base of these preliminary results, it can be concluded that the presence of a multilayer (AlTiN) with higher thickness does not necessarily show beneficial effects against corrosion when compared to a single layer (TiN).

The corrosion behavior of two four-layer PVD coatings is shown in Figure 10. The curves refer to $\mathrm{CrN} / \mathrm{Cr}$ and $\mathrm{CrN} / \mathrm{Nb}$ in $0.1 \mathrm{M} \mathrm{NaCl}$ solution.
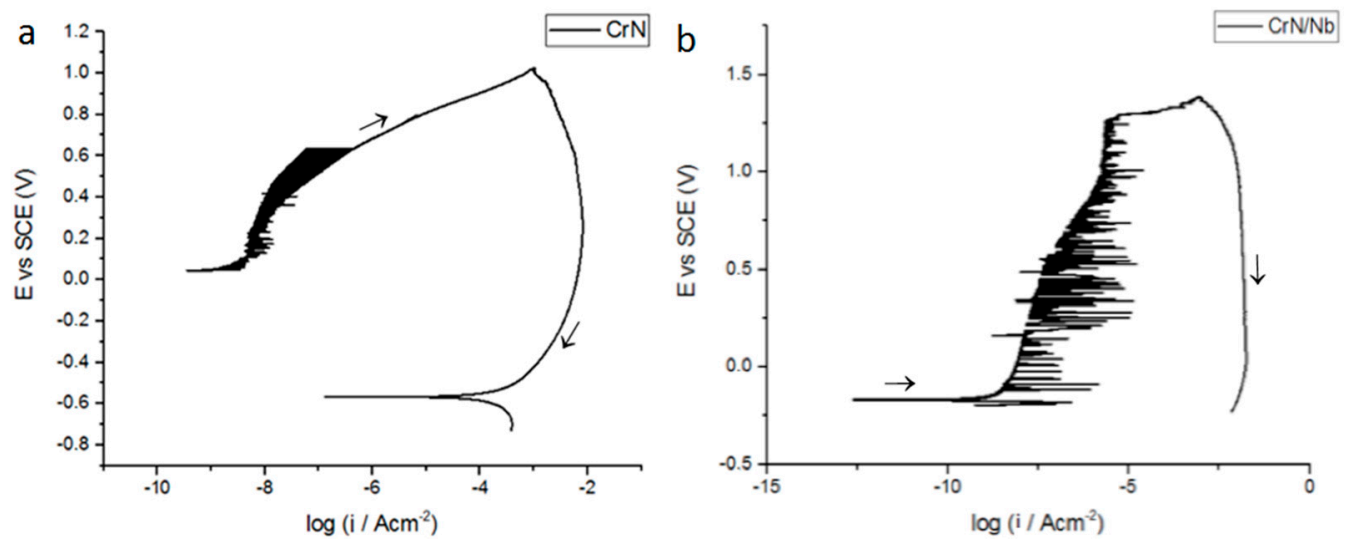

Figure 10. Polarization curves of steel coated with PVD coating $\mathrm{CrN} / \mathrm{Cr}(\mathbf{a})$ and $\mathrm{CrN} / \mathrm{Nb}(\mathbf{b})$ in $0.1 \mathrm{M}$ $\mathrm{NaCl}$ solution.

Both PVD coatings exhibited a similar electrochemical behavior, i.e., a passive zone in the forward branch followed by a negative hysteresis in the reverse one. However, some differences between the two coatings could be underlined. The breakdown potential for $\mathrm{CrN} / \mathrm{Cr}$ was ca. $0.5 \mathrm{~V}$ vs. $\mathrm{SCE}$, while the corresponding value for $\mathrm{CrN} / \mathrm{Nb}$ was markedly higher, close to $1.3 \mathrm{~V}$ vs. SCE. This means that despite the scratch test revealing a certain fragility of the last layer of niobium, the underneath layers appeared sufficiently free of defects, thus leading to a wide passive potential range. Nevertheless, it is worth noting that some oscillations around the passive current density were visible. Accordingly, the long-term stability of the coating could be compromised. These findings could possibly account for the different thicknesses of the two coatings, with $\mathrm{CrN} / \mathrm{Cr}$ being thinner than $\mathrm{CrN} / \mathrm{Nb}$.

The effect of a thick coating on the corrosion behavior is appreciable in Figure 11, where the polarization curve of the single layer $\mathrm{ZrN}$ coating is shown.

This coating had a thickness in the range 3.0-3.5 $\mu \mathrm{m}$, the highest value among the PVD coatings under examination. In spite of the fact that the coating thickness was so high, the electrochemical features were poor, exhibiting a breakdown potential of ca. $0.1 \mathrm{~V}$ vs. SCE and a modest passive potential window.

The corrosion potential of each tested coating as obtained in open circuit conditions are listed in Table 4. The open circuit potential of the coatings showed a remarkable shift to positive values 
compared with that of bare steel, with the latter exhibiting a potential value of $-0.622 \mathrm{~V}$ in $\mathrm{Na}_{2} \mathrm{SO}_{4}$ $(-0.521 \mathrm{~V}$ in $\mathrm{NaCl})$, which was once more typical for an active material subjected to a uniform corrosion process [26-28]. Consequently, the improvement of corrosion resistance of the coatings with respect to the substrate was appreciable. Comparing the open circuit potentials of substrate and PVD coatings, it can be observed that $\mathrm{CrN} / \mathrm{Cr}$ and titanium-based coatings showed less negative values, while $\mathrm{CrN} / \mathrm{Nb}$ had $E_{\text {corr }}=-0.214 \mathrm{~V}$ vs. SCE. This negative potential could be firstly put in relation to the scratch test results, where it was apparent that the last layer of niobium was too fragile, thus leading to possible failure of the overall coating. Indeed, it can be observed that niobium and zirconium had very negative reversible potentials $\left(\mathrm{Zr}^{4+}+4 \mathrm{e}^{-} \rightleftharpoons \mathrm{Zr}(\mathrm{s}) E^{\circ}=-1.45 \mathrm{~V}\right.$ vs. SHE and $\mathrm{Nb}^{3+}+3 \mathrm{e}^{-} \rightleftharpoons \mathrm{Nb}(\mathrm{s}) E^{\circ}=-1.099 \mathrm{~V}$ vs. SHE), thus justifying the observed open circuit potential.

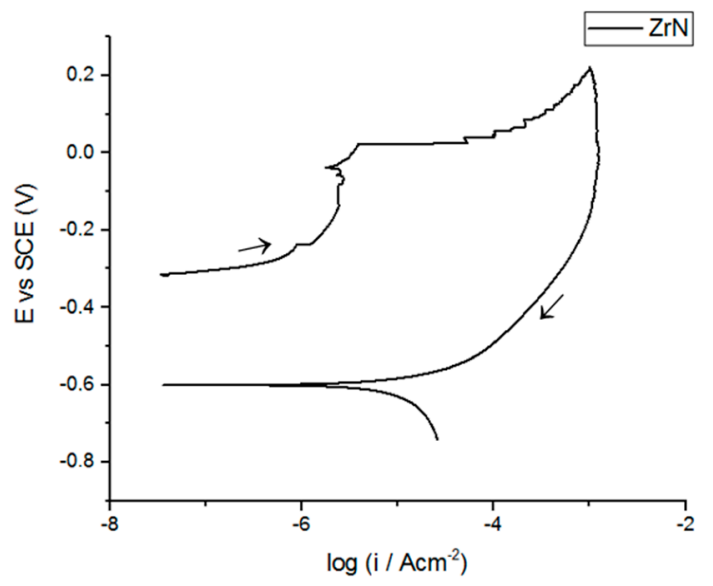

Figure 11. Polarization curves of steel coated with ZrN PVD coating in $0.1 \mathrm{M} \mathrm{NaCl}$ solution.

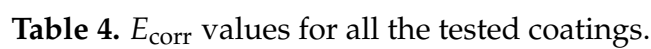

\begin{tabular}{ccc}
\hline Coating & $E_{\text {corr }}(\mathbf{V})$ in $\mathbf{0 . 1} \mathbf{~} \mathbf{~ N a}_{\mathbf{2}} \mathbf{S O}_{\mathbf{4}}$ & $\boldsymbol{E}_{\text {corr }}(\mathbf{V})$ in $\mathbf{0 . 1} \mathbf{~ M ~ N a C l}$ \\
\hline Steel substrate & -0.622 & -0.521 \\
$\mathrm{CrN} / \mathrm{Cr}$ & -0.089 & 0.050 \\
$\mathrm{CrN} / \mathrm{Nb}$ & -0.214 & -0.194 \\
$\mathrm{AlTiN}$ & -0.028 & -0.319 \\
$\mathrm{TiN}$ & -0.022 & -0.253 \\
$\mathrm{ZrN}$ & -0.150 & -0.314 \\
\hline
\end{tabular}

The overall electrochemical features from a strict analysis of every curve are listed in Tables 5 and 6 for PVD coatings in $\mathrm{Na}_{2} \mathrm{SO}_{4}$ and $\mathrm{NaCl}$.

By strict analysis of the reported values, it was possible to confirm the above considerations concerning the corrosion behavior of different PVD coatings.

Table 5. Electrochemical features in $0.1 \mathrm{M} \mathrm{Na}_{2} \mathrm{SO}_{4}$. $E_{\text {corr, }}$, corrosion potential; $E_{\text {prot, }}$ protection potential; $E_{\mathrm{b}}$, breakdown potential; $i_{\mathrm{p}}$, passive current density.

\begin{tabular}{ccccc}
\hline Coating & $\boldsymbol{E}_{\text {corr }}(\mathbf{V})$ & $\boldsymbol{E}_{\text {prot }}(\mathbf{V})$ & $\boldsymbol{E}_{\mathbf{b}}(\mathbf{V})$ & $\boldsymbol{i}_{\mathbf{p}}\left(\mathbf{A} / \mathrm{cm}^{2}\right)$ \\
\hline $\mathrm{AlTiN}$ & $-0.28 \times 10^{-1}$ & 0.39 & 1.35 & $5.73 \times 10^{-8}$ \\
$\mathrm{TiN}$ & $-0.22 \times 10^{-1}$ & 0.56 & 1.37 & $1.40 \times 10^{-8}$ \\
$\mathrm{CrN} / \mathrm{Cr}$ & $-0.89 \times 10^{-1}$ & 0.75 & 0.60 & $7.09 \times 10^{-8}$ \\
$\mathrm{CrN} / \mathrm{Nb}$ & -0.21 & -0.63 & 0.65 & $8.62 \times 10^{-7}$ \\
$\mathrm{ZrN}$ & -0.15 & 0.05 & $>1.4$ & $9.78 \times 10^{-7}$ \\
Steel & -0.62 & -0.72 & - & - \\
\hline
\end{tabular}


Table 6. Electrochemical features in $0.1 \mathrm{M} \mathrm{NaCl}$. $E_{\text {corr, }}$ corrosion potential; $E_{\text {prot}}$, protection potential; $E_{\text {rev }}$, reverse potential; $i_{\mathrm{p}}$, passive current density.

\begin{tabular}{ccccc}
\hline Coating & $\boldsymbol{E}_{\text {corr }}(\mathbf{V})$ & $\boldsymbol{E}_{\text {prot }}(\mathbf{V})$ & $\boldsymbol{E}_{\mathbf{b}}(\mathbf{V})$ & $\left.\boldsymbol{i}_{\mathbf{p}} \mathbf{( A / \mathbf { c m } ^ { 2 }}\right)$ \\
\hline $\mathrm{AlTiN}$ & -0.32 & -0.31 & 0.85 & $1.55 \times 10^{-7}$ \\
$\mathrm{TiN}$ & -0.25 & -0.52 & 1.1 & $8.45 \times 10^{-6}$ \\
$\mathrm{CrN} / \mathrm{Cr}$ & $0.5 \times 10^{-2}$ & -0.55 & 0.5 & $6.23 \times 10^{-8}$ \\
$\mathrm{CrN} / \mathrm{Nb}$ & -0.19 & -0.25 & 1.3 & $4.64 \times 10^{-8}$ \\
$\mathrm{ZrN}$ & -0.31 & -0.6 & $0.5 \times 10^{-1}$ & $4.76 \times 10^{-6}$ \\
Steel & -0.52 & -0.62 & - & - \\
\hline
\end{tabular}

\section{Conclusions}

PVD technology is becoming an emerging alternative for the molding industry to produce hard coatings with improved performance in a more eco-friendly and safe way. In the present work, five PVD coatings were produced and characterized in terms of both corrosion behavior and surface properties. Titanium-based PVD coatings showed the best compromise between good corrosion resistance and remarkable surface properties, making them a promising choice for specific applications in plastic and rubber molding. It is worth noting that the TiN PVD coating studied in the present work was in the form of a monolayer with a thickness comparable to penetration depth. Despite this, its performance was quite encouraging and could be further improved with increasing thickness. In applications where high-localized loads and creeps are expected, it is preferable, as in the case of plastic molds, to choose single layer over multilayer PVD coating to avoid delamination. The same situation is valid for corrosion resistance, where the fragility of the layer can lead to cracks and consequently to localized attacks with a worsening of the protective properties, especially in aggressive environments. Finally, TiN single layer PVD coating exhibited appropriate mechanical properties concerning hardness $\left(913 \pm 110 \mathrm{HV}_{0.01 / 10}\right)$, roughness $\left(R_{\mathrm{a}} 50 \mathrm{~nm}\right)$, and adhesion (LcI $\left.13 \mathrm{~N}\right)$ associated with superior corrosion resistance in tested solutions.

Author Contributions: Conceptualization, S.P.T.; Methodology, S.P.T., N.L. and L.D'A.; Validation, R.B.; Investigation, L.D'A.; Writing-Original Draft Preparation, R.B.; Writing-Review \& Editing, S.P.T. and R.B.; Supervision, S.P.T. and N.L.

Funding: This research received no external funding.

Acknowledgments: The authors would like to thank CRT Srl (Nerviano, Italy) for PVD sample preparation.

Conflicts of Interest: The authors declare no conflict of interest.

\section{References}

1. Mattox, D.M. Handbook of Physical Vapor Deposition (PVD) Processing, 1st ed.; William Andrew Inc.: Oxford, UK, 1998.

2. Meyer, R.W. Handbook of Polyester Molding Compounds and Molding Technology, 2nd ed.; Chapman and Hall Ltd.: London, UK, 2012.

3. Kutz, M. Applied Plastics Engineering Handbook: Processing, Materials, and Applications, 2nd ed.; Elsevier Inc.: Oxford, UK, 2016.

4. Richardson, M.L.; Gangolli, S. The Dictionary of Substances and Their Effects; The Royal Society of Chemistry: Cambridge, UK, 1992.

5. Legg, K.O.; Graham, M.; Chang, P.; Rastagar, F.; Gonzales, A.; Sartwell, B. The replacement of electro-plating. Surf. Coat. Technol. 1996, 81, 99-105. [CrossRef]

6. Bobzin, K.; Michaeli, W.; Bagcivan, N.; Immich, P.; Klaiber, F.; Theiß, S. Chromium based PVD coatings for injection moulding tools. In Friction, Wear and Wear Protection; Fischer, A., Bobzin, K., Eds.; Wiley-VCH: Weinheim, Germany, 2009; pp. 737-743.

7. Sue, J.A. Development of arc evaporation of non-stoichiometric titanium nitride coatings. Surf. Coat. Technol. 1993, 61, 115-120. [CrossRef] 
8. Holleck, H.; Schier, A.V. Multilayer PVD coatings for wear protection. Surf. Coat. Technol. 1995, 76-77, 328-336. [CrossRef]

9. Sproul, W.D. Physical vapor deposition tool coatings. Surf. Coat. Technol. 1996, 81, 1-7. [CrossRef]

10. Wang, Y. A study of PVD coatings and die materials for extended die-casting die life. Surf. Coat. Technol. 1997, 94-95, 60-63. [CrossRef]

11. Su, Y.L.; Yao, S.H.; Wei, C.S.; Wu, C.T.; Kao, W.H. Evaluation on the wear, tension and fatigue behavior of various PVD coated materials. Mater. Lett. 1998, 35, 255-260. [CrossRef]

12. Yoon, S.Y.; Kim, J.K.; Kim, K.H. A comparative study on tribological behavior of TiN and TiAlN coatings prepared by arc ion plating technique. Surf. Coat. Technol. 2002, 161, 237-242. [CrossRef]

13. Rodrıguez, R.J.; Garcıa, J.A.; Medrano, A.; Rico, M.; Sánchez, R.; Martınez, R.; Labrugère, C.; Lahaye, M.; Guetteb, A. Tribological behaviour of hard coatings deposited by arc-evaporation PVD. Vacuum 2002, 67, 559-566. [CrossRef]

14. Mo, J.L.; Zhu, M.H.; Lei, B.; Leng, Y.X.; Huang, N. Comparison of tribological behaviours of AlCrN and TiAlN coatings-deposited by physical vapor deposition. Wear 2007, 263, 1423-1429. [CrossRef]

15. Surzhenkov, A.; Põdra, P.; Sergejev, F.; Saarna, M.; Adoberg, E.; Mikli, V.; Viljus, M.; Kulu, P. Comparative study of the PVD coatings on the plasma nitrided steel. Medziagotyra 2012, 18, 40-44. [CrossRef]

16. Okumiya, M.; Griepentrog, M. Mechanical properties and tribological behavior of TiN-CrAlN and CrN-CrAlN multilayer coatings. Surf. Coat. Technol. 1999, 112, 123-128. [CrossRef]

17. PalDey, S.C.D.S.; Deevi, S.C. Single layer and multilayer wear resistant coatings of (Ti, Al)N: A review. Mater. Sci. Eng. A 2003, 342, 58-79. [CrossRef]

18. Fenker, M.; Balzer, M.; Kappl, H. Corrosion protection with hard coatings on steel: Past approaches and current research efforts. Surf. Coat. Technol. 2014, 257, 182-205. [CrossRef]

19. ASTM G171-03(17) Standard Test Method for Scratch Hardness of Materials Using a Diamond Stylus; ASTM International: West Conshohocken, PA, USA, 2017.

20. Bagcivan, N.; Bobzin, K.; Brögelmann, T.; Kalscheuer, C. Development of (Cr, Al) on coatings using middle frequency magnetron sputtering and investigations on tribological behavior against polymers. Surf. Coat. Technol. 2014, 260, 347-361. [CrossRef]

21. Wänstrand, O.; Larsson, M.; Hedenqvist, P. Mechanical and tribological evaluation of PVD WC/C coatings. Surf. Coat. Technol. 1999, 111, 247-254. [CrossRef]

22. Wu, F.B.; Duh, J.G. Scratch behavior and in situ acoustic emission analysis of PVD chromium nitride coatings on mild steel with electroless nickel interlayers. Surf. Coat. Technol. 2003, 162, 106-112. [CrossRef]

23. Khlifi, K.; Ben Cheikh Larbi, A. Investigation of adhesion of PVD coatings using various approaches. Surf. Eng. 2013, 29, 555-560. [CrossRef]

24. Cunha, L.; Andritschky, M.; Pischow, K.; Wang, Z. Microstructure of CrN coatings produced by PVD techniques. Thin Solid Films 1999, 355-356, 465-471. [CrossRef]

25. Heinke, W.; Leyland, A.; Matthews, A.; Berg, G.; Friedrich, C.; Broszeit, E. Evaluation of PVD nitride coatings, using impact, scratch and Rockwell-C adhesion tests. Thin Solid Films 1995, 270, 431-438. [CrossRef]

26. Naghibi, S.A.; Raeissi, K.; Fathi, M.H. Corrosion and tribocorrosion behavior of Ti/TiN PVD coating on 316L stainless steel substrate in ringer's solution. Mater. Chem. Phys. 2014, 148, 614-623. [CrossRef]

27. Ahn, S.H.; Yoo, J.H.; Choi, Y.S.; Kim, J.G.; Han, J.G. Corrosion behavior of PVD-grown WC-( $\left.\mathrm{Ti}_{1-x} \mathrm{Al}_{x}\right) \mathrm{N}$ films in a 3.5\% NaCl solution. Surf. Coat. Technol. 2003, 162, 212-221. [CrossRef]

28. Hack, H.P. Evaluation of galvanic corrosion. In Metals Handbook, 9th ed.; Gegel, H.L., Malas, J.C., Doraivelu, S.M., Shende, V.A., Eds.; ASM International: Materials Park, OH, USA, 1989; Volume 13, pp. 234-238.

(C) 2018 by the authors. Licensee MDPI, Basel, Switzerland. This article is an open access article distributed under the terms and conditions of the Creative Commons Attribution (CC BY) license (http:/ / creativecommons.org/licenses/by/4.0/). 